\title{
Obesity increases the incidence of distant metastases in oestrogen receptor-negative human epidermal growth factor receptor 2-positive breast cancer patients
}

\author{
Luca Mazzarella $^{\mathrm{a}, \mathrm{b}, *}$, Davide Disalvatore ${ }^{\mathrm{c}}$, Vincenzo Bagnardi ${ }^{\mathrm{c}, \mathrm{d}}$, Nicole Rotmensz ${ }^{\mathrm{c}}$, \\ Donata Galbiati $^{\mathrm{e}}$, Sara Caputo ${ }^{\mathrm{b}}$, Giuseppe Curigliano ${ }^{\mathrm{a}, *}$, Pier Giuseppe Pelicci ${ }^{\mathrm{b}, \mathrm{f}, *}$
}

\footnotetext{
${ }^{a}$ Division of Medical Oncology, Istituto Europeo di Oncologia, Milan, Italy

${ }^{\mathrm{b}}$ Department of Experimental Oncology, Istituto Europeo di Oncologia, Milan, Italy

${ }^{\mathrm{c}}$ Division of Epidemiology and Biostatistics, Istituto Europeo di Oncologia, Milan, Italy

${ }^{\mathrm{d}}$ Department of Statistics and Quantitative Methods, University of Milan-Bicocca, Milan, Italy

e The Falck Division of Medical Oncology, Ospedale Niguarda Ca' Granda, Milan, Italy

${ }^{\mathrm{f}}$ Dipartimento di Medicina, Chirurgia e Odontoiatria, Università degli Studi di Milano, 20122 Milan, Italy
}

\section{KEYWORDS \\ Body mass index Breast neoplasms HER2 \\ Obesity}

\begin{abstract}
Background: Obesity is a major negative determinant of breast cancer outcome. However, there are contrasting data on the differential impact of obesity on specific breast cancer subtypes. In particular, very little is known on human epidermal growth factor receptor 2-positive (HER2+) tumours.

Patients and methods: We assessed the prognostic role of increased body mass index (BMI) on a consecutive series of non-metastatic HER2+ patients treated at our institution before the introduction of adjuvant Trastuzumab. We separately analysed oestrogen receptor-positive $(\mathrm{ER}+)$ and -negative $(\mathrm{ER}-) \mathrm{HER} 2+$ cases.

Results: In ER-/HER2+ tumours we observed a significantly worse overall survival (Hazard ratio (HR) 1.79, $p$-value 0.041) and cumulative incidence of distant metastases (HR 2.03, $p$-value 0.019$)$ in obese $(\mathrm{BMI}>30)$ versus normal/underweight $(\mathrm{BMI}<25)$ patients. Local relapses appeared to be non-significantly reduced in obese patients, masking the overall effect on disease-free survival. Outcome in ER+ tumours, instead, was not significantly different between BMI groups.

Conclusions: Obesity significantly correlates with worse overall survival and cumulative incidence of distant metastases in ER-/HER2 positive breast cancer. Differences in the biology
\end{abstract}

\footnotetext{
* Corresponding authors: Address: Department of Experimental Oncology, IFOM-IEO Campus, Via Adamello 16, 20139 Milan, Italy. Tel.: +39 029437 5083; fax: +39 0294375991 (L. Mazzarella), tel.: +39 029437 2056; fax: +39 0294375991 (P.G. Pelicci). Address: Division of Medical Oncology, European Institute of Oncology, Via Ripamonti 435, 20141 Milano, Italy. Tel.: +39 0257489599 ; fax: +39 0294379224 (G. Curigliano).

E-mail addresses: luca.mazzarella@ieo.eu (L. Mazzarella), giuseppe.curigliano@ieo.it (G. Curigliano), piergiuseppe.pelicci@ieo.eu
} (P.G. Pelicci). 
of breast tumours may determine individual susceptibility to obesity. The biology of the underlying tumour should be taken into account in the design of dietary intervention trials in breast cancer.

(c) 2013 Elsevier Ltd. All rights reserved.

\section{Introduction}

Besides its established role as a risk factor, there is now widespread consensus on the importance of obesity as a negative prognostic factor for breast cancer. ${ }^{1-3}$ This recognition has provided a strong rationale for past and on-going studies on the metabolic control of breast cancer patients through dietary or pharmacological interventions. $^{4-7}$

Breast cancer is, however, a biologically heterogeneous disease in which treatment modalities are dictated by molecular features; ${ }^{8}$ definitive evidence is still lacking on the impact of obesity on specific breast cancer types. Studies including information on oestrogen receptor (ER)-positive versus -negative tumours were meta-analysed by Niraula et $\mathrm{al}^{2}$ The authors concluded that the receptor status did not significantly alter the obesity effect on overall survival (OS) (obese/normal hazard ratio (HR): 1.31 and 1.18 in ER+ and ER-, respectively) or on breast cancer-specific survival (BCSS) (obese/normal HR: 1.36 and 1.46 in ER+ and ER-, respectively). However, there was substantial heterogeneity among the studies included in the analysis, due to differences in body mass index (BMI) categorisation and variability in the definition of the ER - disease, with early studies considering tumours with $<10 \%$ ER expression as ER negative, contrarily to current guidelines. ${ }^{8}$ Individual studies did in fact observe differences between ER+ and ER - groups. ${ }^{9,10}$

If differential effects according to hormone receptor status are still a matter of debate, even less is known on human epidermal growth factor receptor 2-positive (HER2+) tumours. In the present study, we assessed the prognostic role of increased BMI on a consecutive series of non-metastatic HER2+ patients treated at our institution. As the introduction of targeted therapy has radically altered the natural history of this disease, we decided to limit our analysis to patients treated before the introduction of Trastuzumab adjuvant therapy. ER+ and ER - HER2+ tumours were separately analysed, as they constitute clinically and biologically distinct groups. ${ }^{811}$ Surprisingly, a role for obesity could be observed only in ER - tumours, with a significantly worse OS and an increased risk of distant metastases.

\section{Patients and methods}

We systematically collected information on all consecutive breast cancer patients operated at the European Institute of Oncology in a dedicated data base, thus we had access to the clinical data of interest (from 1995 to 2005 , prior to Trastuzumab adjuvant therapy). We identified 1250 HER $2+$ early stage breast cancer patients operated during this period for whom data were available regarding weight and height, which we used to calculate the BMI [weight in kilograms/(height in metres) ${ }^{2}$ ]. Data were also available regarding age, menopausal state, date of surgery, tumour characteristics (histological type, tumour size, nodal involvement, grade, perivascular infiltration, Ki-67 and ER/progesterone receptor (PgR) expression) and treatment modality (type of surgery, adjuvant radiotherapy, endocrine therapy and chemotherapy).

Patients' follow-up included: physical examination every 6 months, annual mammography and breast ultrasound, blood tests every 6-12 months and, in case of symptoms, further evaluation. When possible, the status of those women not attending the scheduled follow-up visits at the institute for more than one year was obtained by telephone contact. Forty patients $(3.2 \%)$ were lost to follow-up. The median length of follow-up was 8.2 years. The study was approved by the Institutional Review Board.

\subsection{Statistics}

Patients were assigned to BMI groups, according to the standard World Health Organisation (WHO) categorisation, ${ }^{12}$ as follows: underweight (BMI $<18.5$ ), normal weight (BMI between 18.5 and 24.99), overweight (BMI between 25 and 29.99) and obese (BMI $\geqslant 30$ ).

Differences in the distribution of subject characteristics between groups were evaluated by the Chi-square test.

End-points included disease-free survival (DFS), overall survival (OS), cumulative incidence of local or regional recurrence (CI-LR) and distant metastases (CI-DM). DFS was defined as the time from surgery to events such as relapse (including ipsilateral breast recurrence), appearance of a second primary cancer (including contralateral breast cancer), or death, whichever occurred first. OS was defined as the time from surgery until the date of death (from any cause). DFS and OS functions were estimated using the Kaplan-Meier method. The log-rank test was used to assess differences between groups. The CI-LR and CI-DM were defined as the time from surgery to the appearance of a local or regional recurrence and distant metastases, respectively.

CI-LR and CI-DM functions were estimated according to methods described by Kalbfleisch and Prentice, ${ }^{13}$ 
taking into account the competing causes of recurrence. The Gray's test was used to assess cumulative incidence differences between groups.

The hazard ratios (HRs,) comparing obese patients versus under/normal weight patients and overweight patients versus under/normal weight patients, were estimated using a Cox proportional hazards multivariable model, controlled for age at diagnosis, menopausal status, number of positive lymph nodes, tumour size, grade, percent of oestrogen receptor-positive cells (as a continuous variable), perivascular invasion and type of surgery.

In order to investigate the shape of the relationship between BMI and the hazard of the considered outcomes, multivariable Cox second-order fractional polynomial models were used. ${ }^{14}$ Briefly, second-order fractional polynomial models are a family of models generated from power transformations of a continuous exposure variable (in our case BMI), restricted to a predefined set of exponents (in our case the following exponents were tested: $-2,-1,-0.5,0,0.5,1,2$ and $3)$. The best fit among the family of models generated from the combinations of exponents is defined as that with the lowest residual deviance. The family offers considerably flexibility, since a rich set of possible functions, including some 'U-shaped' and 'J-shaped' relations, may be accommodated.

All analyses were carried out with the SAS software (SAS Institute, Cary, NC) and the R software (http:// cran.r-project.org/) with the cmprsk package developed by Gray (http://biowww.dfci.harvard.edu/ gray/). All reported $p$-values are two-sided.

\section{Results}

\subsection{Study population}

Table 1 lists selected demographic, clinical and pathological characteristics and local and systemic treatments of the study population at the time of surgery $(n=1250)$, categorised according to oestrogen receptor (ER) status and WHO BMI classes: normal-underweight $(\mathrm{BMI}<25)$, overweight $(25 \leqslant \mathrm{BMI}<30)$ and obese $(\mathrm{BMI} \geqslant 30)$. Underweight patients were grouped together with normal weight as only 53 patients had a BMI $<18.5$.

The prevalence of obese patients in our cohort was $8.1 \%$, in line with the overall prevalence of obesity in the Italian population. ${ }^{15,16}$ BMI showed a significantly different distribution $(p=0.0032)$ between the 759 patients with ER positive breast cancer and the 491 patients with ER negative breast cancer $(19.5 \%$ and $7.8 \%$ of overweight and obese patients, respectively, in the ER positive group and $26.7 \%$ and $9.6 \%$ of overweight and obese patients, respectively, in the ER negative group).
No significant differences were found in either group as regards primary tumour size, lymph node involvement, grade, perivascular invasion or Ki-67 score. Obese and overweight patients were on average significantly older than normal/underweight patients both in the ER positive $(p<0.001)$ and ER negative group $(p<0.001)$. Accordingly, menopausal status was significantly associated with BMI distribution in both groups.

Obese and overweight patients were more likely to have undergone conservative surgery than normalunderweight patients $[83.1 \%, 75.7 \%$ and $67 \%$, respectively, in the ER positive group $(p=0.009)$, and $66 \%$, $67.9 \%$ and $58.5 \%$ in the ER negative group $(p=0.142)]$. No significant differences were noted for adjuvant systemic therapy. However, in the ER positive group, obese patients were more likely to receive anthracycline-containing chemotherapy $(22 \%$ versus $12 \%$ of overweight and normal-underweight patients, $p=0.043$ ). None of the patients received Trastuzumab in the adjuvant setting.

\subsection{Recurrence in ER+/HER2+ tumours}

Overall, 246 first events were observed among the 759 patients with HER2 positive, ER positive breast cancer during the follow-up period (Table 2), with 68 local or regional recurrences, 112 distant metastases and 66 other events ( 15 contralateral breast cancers, $40 \mathrm{~s}$ primaries and 11 deaths from causes other than breast cancer). 118 patients died during the follow-up.

No significant differences in OS or DFS could be observed among the three BMI groups. The 5-year OS proportions were $93.4 \%$ (95\% confidence interval (CI): $91.0-95.2 \%)$ in the under/normal weight patients, 94.6\% (95\% CI: 89.4-97.2\%) in the overweight patients and $93.2 \%(95 \%$ CI: $82.9-97.4 \%)$ in the obese patients ( $p$-value 0.849) (Fig. 1A).

The 5-year DFS proportions were $74.8 \%$ (95\% CI: $70.9-78.2 \%)$ in the under/normal weight patients, $76.7 \%$ (95\% CI: $68.9-82.7 \%$ ) in the overweight patients and $83.9 \%(95 \%$ CI: $71.2-91.3 \%)$ in the obese patients ( $p$-value 0.554) (Fig. 1B).

We then separated first events into local/regional and distant recurrences and computed the 5-year cumulative incidences. No local recurrence was recorded among obese patients. In contrast, an incidence of $4.1 \%(95 \%$ CI: $1.0-9.9 \%)$ and $6.9 \%(95 \%$ CI: $5.0-9.4 \%$ ) was observed, respectively, in the overweight patients and in the under/normal weight patients; however the differences between the three groups were not statistically significant (Gray test $p$-value 0.273) (Fig. 1C). The 5-year CI-DM was comparable in the three groups (Gray test $p$-value 0.725) (Fig. 1D). 
Table 1

Baseline characteristics and treatment of patients, by oestrogen receptor status and body mass index (BMI) category. ${ }^{\mathrm{a}}$

\begin{tabular}{|c|c|c|c|c|c|c|c|c|}
\hline \multirow[t]{2}{*}{ Variable } & \multicolumn{4}{|c|}{ ER positive $(\geqslant 1 \%)$} & \multicolumn{4}{|l|}{ ER negative } \\
\hline & $\begin{array}{l}\text { Under/normal } \\
\text { weight } \\
N=552 \\
N(\%) \\
\end{array}$ & $\begin{array}{l}\text { Overweight } \\
N=148 \\
N(\%)\end{array}$ & $\begin{array}{l}\text { Obese } \\
\begin{array}{l}N=59 \\
N(\%)\end{array}\end{array}$ & $p^{*}$ & $\begin{array}{l}\text { Under/normal } \\
\text { weight } \\
N=313 \\
N(\%) \\
\end{array}$ & $\begin{array}{l}\text { Overweight } \\
N=131 \\
N(\%)\end{array}$ & $\begin{array}{l}\text { Obese } \\
\begin{array}{l}N=47 \\
N(\%)\end{array}\end{array}$ & $p$ \\
\hline Age at surgery & & & & $<0.001$ & & & & $<0.001$ \\
\hline$<35$ & $49(8.9)$ & $4(2.7)$ & $0(0)$ & & $18(5.8)$ & $2(1.5)$ & $0(0)$ & \\
\hline $35-50$ & $290(52.5)$ & $40(27)$ & $19(32.2)$ & & $138(44.1)$ & $35(26.7)$ & $11(23.4)$ & \\
\hline $51-65$ & $175(31.7)$ & $84(56.8)$ & $35(59.3)$ & & $124(39.6)$ & $73(55.7)$ & $25(53.2)$ & \\
\hline$>65$ & $38(6.9)$ & $20(13.5)$ & $5(8.5)$ & & $33(10.5)$ & $21(16)$ & $11(23.4)$ & \\
\hline Menopausal status & & & & $<0.001$ & & & & $<0.001$ \\
\hline Premenopausal & $325(58.9)$ & $48(32.4)$ & $13(22)$ & & $149(47.6)$ & $32(24.4)$ & $10(21.3)$ & \\
\hline Postmenopausal & $227(41.1)$ & $100(67.6)$ & $46(78)$ & & $164(52.4)$ & 99 (75.6) & $37(78.7)$ & \\
\hline Year of Surgery & & & & 0.632 & & & & 0.890 \\
\hline$<1998$ & $4(0.7)$ & $1(0.7)$ & $0(0)$ & & $6(1.9)$ & $2(1.5)$ & $0(0)$ & \\
\hline $1998-2001$ & $206(37.3)$ & $58(39.2)$ & $17(28.8)$ & & $120(38.3)$ & $51(38.9)$ & $17(36.2)$ & \\
\hline $2002-2005$ & $342(62)$ & $89(60.1)$ & $42(71.2)$ & & $187(59.7)$ & $78(59.5)$ & $30(63.8)$ & \\
\hline Histology & & & & 0.829 & & & & 0.804 \\
\hline Ductal & $502(90.9)$ & $138(93.2)$ & $52(88.1)$ & & $288(92)$ & $116(88.5)$ & $42(89.4)$ & \\
\hline Lobular & $19(3.4)$ & $2(1.4)$ & $2(3.4)$ & & $4(1.3)$ & $2(1.5)$ & $1(2.1)$ & \\
\hline Mixed & $13(2.4)$ & $4(2.7)$ & $2(3.4)$ & & $0(0)$ & $0(0)$ & $0(0)$ & \\
\hline Other & $18(3.3)$ & $4(2.7)$ & $3(5.1)$ & & $21(6.7)$ & $13(9.9)$ & $4(8.5)$ & \\
\hline$p T$ & & & & 0.382 & & & & 0.380 \\
\hline pTX & $2(0.4)$ & $0(0)$ & $1(1.7)$ & & $4(1.3)$ & $3(2.3)$ & $2(4.3)$ & \\
\hline pT1 & $314(56.9)$ & $79(53.4)$ & $26(44.1)$ & & $175(55.9)$ & $66(50.4)$ & $20(42.6)$ & \\
\hline pT2 & $198(35.9)$ & $60(40.5)$ & $29(49.2)$ & & $113(36.1)$ & $47(35.9)$ & $20(42.6)$ & \\
\hline pT3 & $32(5.8)$ & $8(5.4)$ & $3(5.1)$ & & $17(5.4)$ & $14(10.7)$ & $4(8.5)$ & \\
\hline pT4 & $6(1.1)$ & $1(0.7)$ & $0(0)$ & & $4(1.3)$ & $1(0.8)$ & $1(2.1)$ & \\
\hline Positive lymph nodes & & & & 0.728 & & & & 0.696 \\
\hline Unknown & $11(2)$ & $4(2.7)$ & $0(0)$ & & $5(1.6)$ & $2(1.5)$ & $0(0)$ & \\
\hline None & $283(51.3)$ & $67(45.3)$ & $31(52.5)$ & & $159(50.8)$ & $63(48.1)$ & $18(38.3)$ & \\
\hline $1-3$ & $159(28.8)$ & $49(33.1)$ & $19(32.2)$ & & $71(22.7)$ & $32(24.4)$ & $13(27.7)$ & \\
\hline $4+$ & 99 (17.9) & $28(18.9)$ & $9(15.3)$ & & $78(24.9)$ & $34(26)$ & $16(34)$ & \\
\hline Grade & & & & 0.311 & & & & 0.888 \\
\hline Unknown & $13(2.4)$ & $1(0.7)$ & $3(5.1)$ & & $14(4.5)$ & $4(3.1)$ & $1(2.1)$ & \\
\hline $1-2$ & $240(43.5)$ & $65(43.9)$ & $19(32.2)$ & & $61(19.5)$ & $26(19.8)$ & $8(17)$ & \\
\hline 3 & $299(54.2)$ & $82(55.4)$ & $37(62.7)$ & & $238(76)$ & $101(77.1)$ & $38(80.9)$ & \\
\hline$P V I$ & & & & 0.480 & & & & 0.471 \\
\hline Unknown & $1(0.2)$ & $0(0)$ & $1(1.7)$ & & $3(1)$ & $2(1.5)$ & $2(4.3)$ & \\
\hline Absent & $335(60.7)$ & $94(63.5)$ & 43 (72.9) & & $204(65.2)$ & $81(61.8)$ & 27 (57.4) & \\
\hline Present & $28(5.1)$ & $5(3.4)$ & $2(3.4)$ & & $6(1.9)$ & $3(2.3)$ & $1(2.1)$ & \\
\hline Focal & $96(17.4)$ & $27(18.2)$ & $5(8.5)$ & & $36(11.5)$ & $24(18.3)$ & $9(19.1)$ & \\
\hline Diffuse & $92(16.7)$ & $22(14.9)$ & $8(13.6)$ & & $64(20.4)$ & $21(16)$ & $8(17)$ & \\
\hline$P g R$ & & & & 0.428 & & & & 0.621 \\
\hline Unknown & $0(0)$ & $0(0)$ & $0(0)$ & & $1(0.3)$ & $0(0)$ & $0(0)$ & \\
\hline $\mathrm{PgR}=0$ & $160(29)$ & $46(31.1)$ & $13(22)$ & & $306(97.8)$ & $129(98.5)$ & $47(100)$ & \\
\hline $\operatorname{PgR}>0$ & $392(71)$ & $102(68.9)$ & $46(78)$ & & $6(1.9)$ & $2(1.5)$ & $0(0)$ & \\
\hline$K i-67$ & & & & 0.581 & & & & 0.407 \\
\hline Unknown & $2(0.4)$ & $0(0)$ & $1(1.7)$ & & $7(2.2)$ & $4(3.1)$ & $2(4.3)$ & \\
\hline$<14 \%$ & $48(8.7)$ & $17(11.5)$ & $5(8.5)$ & & $11(3.5)$ & $3(2.3)$ & $3(6.4)$ & \\
\hline$\geqslant 14 \%$ & $502(90.9)$ & $131(88.5)$ & $53(89.8)$ & & $295(94.2)$ & $124(94.7)$ & $42(89.4)$ & \\
\hline Surgery & & & & 0.009 & & & & 0.142 \\
\hline Conservative & $370(67)$ & $112(75.7)$ & $49(83.1)$ & & $183(58.5)$ & $89(67.9)$ & $31(66)$ & \\
\hline Mastectomy & $182(33)$ & $36(24.3)$ & $10(16.9)$ & & $130(41.5)$ & $42(32.1)$ & $16(34)$ & \\
\hline Radiotherapy & & & & 0.515 & & & & 0.542 \\
\hline Unknown & $14(2.5)$ & $7(4.7)$ & $1(1.7)$ & & $7(2.2)$ & $7(5.3)$ & $5(10.6)$ & \\
\hline No & $108(19.6)$ & 28 (18.9) & $8(13.6)$ & & $92(29.4)$ & $31(23.7)$ & $11(23.4)$ & \\
\hline Yes & $430(77.9)$ & $113(76.4)$ & $50(84.7)$ & & $214(68.4)$ & $93(71)$ & $31(66)$ & \\
\hline
\end{tabular}


Table 1 (continued)

\begin{tabular}{|c|c|c|c|c|c|c|c|c|}
\hline \multirow[t]{3}{*}{ Variable } & \multicolumn{4}{|c|}{ ER positive $(\geqslant 1 \%)$} & \multicolumn{4}{|l|}{ ER negative } \\
\hline & $\begin{array}{l}\text { Under/normal } \\
\text { weight }\end{array}$ & Overweight & Obese & & $\begin{array}{l}\text { Under/normal } \\
\text { weight }\end{array}$ & Overweight & Obese & \\
\hline & $\begin{array}{l}N=552 \\
N(\%)\end{array}$ & $\begin{array}{l}N=148 \\
N(\%)\end{array}$ & $\begin{array}{l}N=59 \\
N(\%)\end{array}$ & $p^{*}$ & $\begin{array}{l}N=313 \\
N(\%)\end{array}$ & $\begin{array}{l}N=131 \\
N(\%)\end{array}$ & $\begin{array}{l}N=47 \\
N(\%)\end{array}$ & $p$ \\
\hline Adjuvant treatment & & & & 0.846 & & & & 0.963 \\
\hline Nil & $15(2.7)$ & $4(2.7)$ & $1(1.7)$ & & $54(17.3)$ & $23(17.6)$ & $6(12.8)$ & \\
\hline Hormonotherapy & $157(28.4)$ & $48(32.4)$ & $21(35.6)$ & & $1(0.3)$ & $0(0)$ & $0(0)$ & \\
\hline Chemotherapy & $20(3.6)$ & $6(4.1)$ & $1(1.7)$ & & 243 (77.6) & 103 (78.6) & $39(83)$ & \\
\hline $\begin{array}{l}\text { Chemotherapy and } \\
\text { hormonotherapy }\end{array}$ & $360(65.2)$ & $90(60.8)$ & $36(61)$ & & $15(4.8)$ & $5(3.8)$ & $2(4.3)$ & \\
\hline $\begin{array}{l}\text { Anthracycline-containing } \\
\text { regimen }^{\$}\end{array}$ & & & & 0.043 & & & & 0.945 \\
\hline Yes & $305(82.1)$ & $75(81.1)$ & $24(65.0)$ & & $190(75.0)$ & $78(76.0)$ & $30(73.0)$ & \\
\hline No & $67(18.0)$ & $18(19.0)$ & $13(35.0)$ & & $65(25.0)$ & $25(24.0)$ & $11(27.0)$ & \\
\hline
\end{tabular}

Abbreviations: ER, oestrogen receptors; PgR, progesterone receptors; PVI, peritumoural vascular invasion.

${ }^{\text {a }}$ Under/normal weight: $\mathrm{BMI}<25$; overweight: $25 \leqslant \mathrm{BMI}<30$; obese: $\mathrm{BMI} \geqslant 30$.

* Chi-square test comparing proportions between BMI categories. $p$-Value were calculated excluding unknown values.

${ }^{\$}$ Evaluated only in patients receiving adjuvant chemotherapy.

\subsection{Recurrence in ER-/HER2+ tumours}

Overall, 194 first events were observed among the 491 patients with HER2 positive, ER negative breast cancer during the follow-up period (Table 2), with 52 local or regional recurrences, 104 distant metastases and 38 other events ( 10 contralateral breast cancers, $14 \mathrm{~s}$ primaries and 14 deaths from causes other than breast cancer). 122 patients died during the follow-up.

Within this group of patients, outcome differences between obese patients and the remaining BMI groups were more pronounced. The 5-year OS proportions were 85.9\% (95\% CI: 81.6-89.3\%) in the under/normal weight patients, $82.4 \%(95 \% \mathrm{CI}: 74.7-87.9 \%)$ in the overweight patients, and $73.5 \%$ (95\% CI: $58.1-84.0 \%)$ in the obese patients ( $p$-value 0.041) (Fig. 2A).

The 5-year DFS proportions were 69.1\% (95\% CI: $63.6-73.9 \%)$ in the under/normal weight patients, $68.1 \%$ (95\% CI: $59.3-75.4 \%)$ in the overweight patients and $55.2 \%(95 \%$ CI: $39.6-68.4 \%)$ in the obese patients ( $p$-value 0.170) (Fig. 2B).

Separate analysis of local/regional and distant recurrences revealed a higher 5-year CI-DM in obese patients (33.4\%, 95\% CI: $22.1-50.5 \%)$ than in overweight (17.9\%,
95\% CI: $12.3-25.9 \%$ ) and under/normal weight patients (17.5\%, 95\% CI: $13.8-22.4 \%)$. The Gray test $p$-value was 0.019 (Fig. 2D).

Similar to ER+/HER2+ patients, we observed fewer local recurrences in obese patients, with a 5 -year CI-LR of $2.3 \%$ (95\% CI: $0.3-16.0 \%$ ) versus $7.8 \%$ (95\% CI: $4.3-$ $14.1 \%)$ in the overweight and $10.4 \%(95 \%$ CI: $7.5-$ $14.5 \%$ ) in the under/normal weight patients. However, the differences between the three groups were not statistically significant (Gray test $p$-value 0.205) (Fig. 2C).

The multivariable analyses (table 3 ) confirmed the results observed in the univariate analysis: the adjusted risk of death and distant metastases were significantly higher in the obese patients than in the under/normal weight patients (HR for death: 1.79, 95\% CI: 1.033.10; HR for distant metastases: 2.03 , 95\% CI: $1.13-$ 3.63 ), whereas the risk of local/regional events was lower, albeit not statistically significant (adjusted obese versus under/normal weight HR: 0.37, 95\% CI: 0.09-1.55).

\subsection{BMI as a continuous variable}

We sought to better characterise the strong association we observed between obesity and distant metastases

Table 2

Observed events, by oestrogen receptor status and body mass index (BMI) category ${ }^{\mathrm{a}}$.

\begin{tabular}{|c|c|c|c|c|c|c|}
\hline \multirow[t]{2}{*}{ Variable } & \multicolumn{3}{|c|}{ Oestrogen receptor-positive $(\mathrm{ER}+)(\geqslant 1 \%)$} & \multicolumn{3}{|l|}{ ER negative (ER-) } \\
\hline & $\begin{array}{l}\text { Under/normal weight } \\
N=552 \\
N(\%)\end{array}$ & $\begin{array}{l}\text { Overweight } \\
N=148 \\
N(\%)\end{array}$ & $\begin{array}{l}\text { Obese } \\
N=59 \\
N(\%)\end{array}$ & $\begin{array}{l}\text { Under/normal weight } \\
N=313 \\
N(\%)\end{array}$ & $\begin{array}{l}\text { Overweight } \\
N=131 \\
N(\%)\end{array}$ & $\begin{array}{l}\text { Obese } \\
N=47 \\
N(\%)\end{array}$ \\
\hline Observed first event & $184(33.3)$ & $47(31.8)$ & $15(25.4)$ & $121(38.7)$ & $49(37.4)$ & $24(51.1)$ \\
\hline Local and regional event & $54(9.8)$ & $12(8.1)$ & $2(3.4)$ & $38(12.1)$ & $12(9.2)$ & $2(4.3)$ \\
\hline Distant metastases & $85(15.4)$ & $20(13.5)$ & $7(11.9)$ & $62(19.8)$ & $25(19.1)$ & $17(36.2)$ \\
\hline Other events ${ }^{\mathrm{b}}$ & $45(8.2)$ & $15(10.1)$ & $6(10.2)$ & $21(6.7)$ & $12(9.2)$ & $5(10.6)$ \\
\hline Total observed deaths & $87(15.8)$ & $21(14.2)$ & $10(16.9)$ & $71(22.7)$ & $33(25.2)$ & $18(38.3)$ \\
\hline
\end{tabular}

${ }^{a}$ Under/normal weight: $\mathrm{BMI}<25$; overweight: $25 \leqslant \mathrm{BMI}<30$; obese: $\mathrm{BMI} \geqslant 30$.

b Including death as first event. 
A

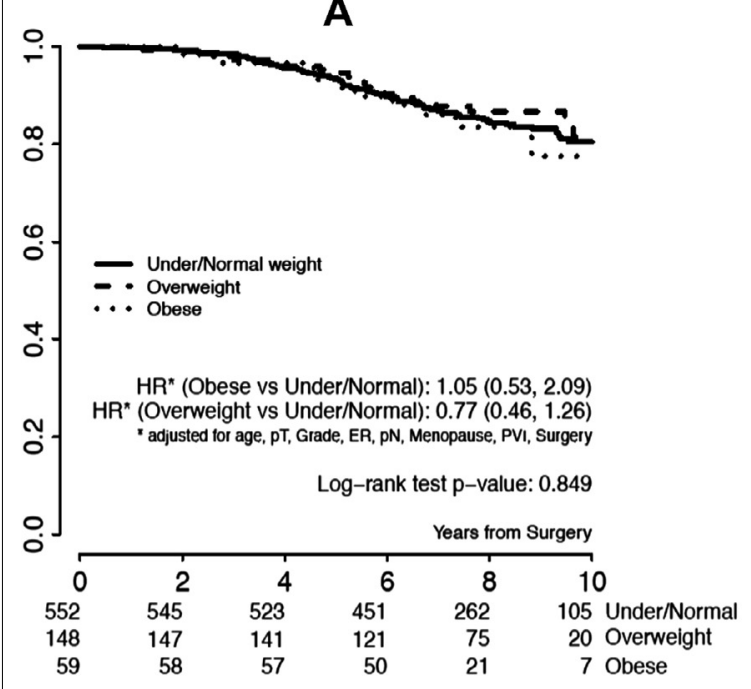

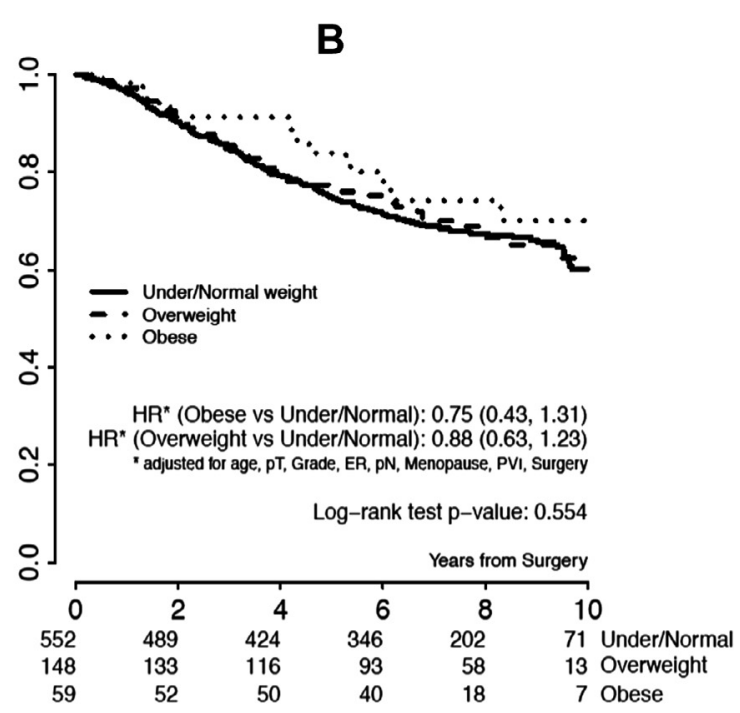

D

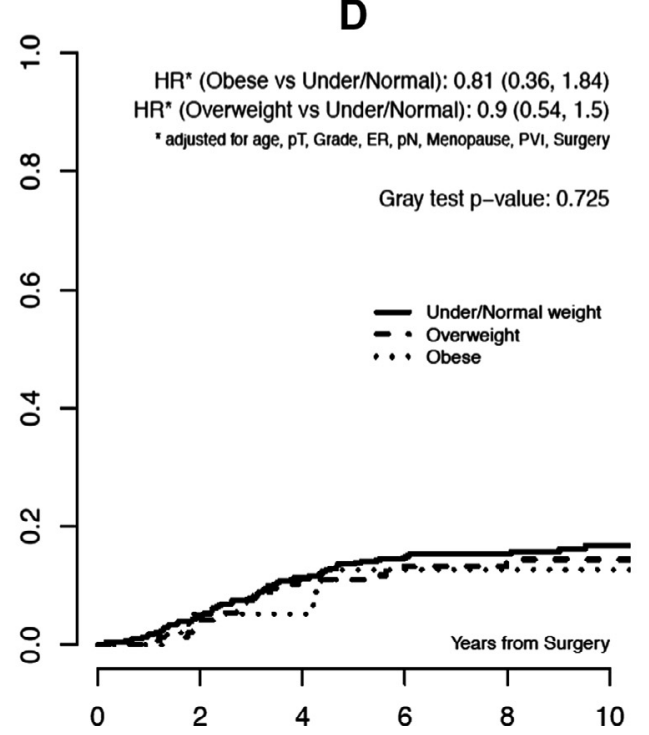

Fig. 1. Overall survival (panel A), disease-free survival (panel B), cumulative incidence of local and regional (LR) recurrence (panel C) and cumulative incidence of distant metastasis (DM) (Panel D), for the 759 patients with oestrogen receptor-positive (ER+)/human epidermal growth factor receptor 2-positive (HER2+) breast cancer, by body mass index category. Univariate log-rank and Gray test $p$-values and hazard ratios (HRs) adjusted for age, pT, Grade, ER, pN, Menopause, peritumoural vascular invasion (PVI), Surgery, are reported.

in ER - tumours by treating BMI as a continuous variable, using second-order multivariable fractional polynomial models (Fig. 3).

The relationship between BMI and HR appeared as a U-shaped curve, increasing non-linearly both at high and low BMI values. When we computed the point-wise $95 \%$ confidence intervals, the right branch of the curve became significant (lower HR CI bound $>1.00$ ) at a BMI value of approximately 27.5 (HR: $1.18,95 \% \mathrm{CI}$ : $1.01-1.37$, when compared with the median BMI value of 24.2), after which the HR continued to grow exponentially with the BMI; on the left side, because of the small number of underweight patients, $95 \%$ CIs were much wider and included the 1.00 threshold at any value. The fractional polynomial model fit the data significantly better than the conventional linear model $(p=0.042)$. Similar analyses with BMI as a continuous variable did not show significant results either in ER+ tumours, or when we studied DFS or the incidence of local events (not shown).

\section{Discussion}

Little information is available on the impact of BMI on outcome in HER2+ breast cancer.

In this study, we have examined a consecutive series of 1250 patients treated at our institution before 2006, prior to the introduction of adjuvant Trastuzumab. This time frame was chosen in order to provide long term follow-up information and to minimise any potential 
A

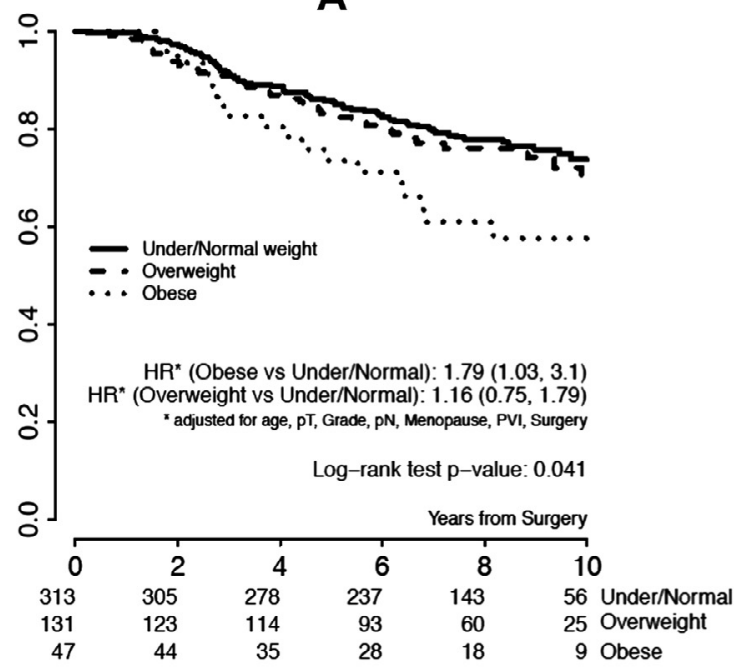

B

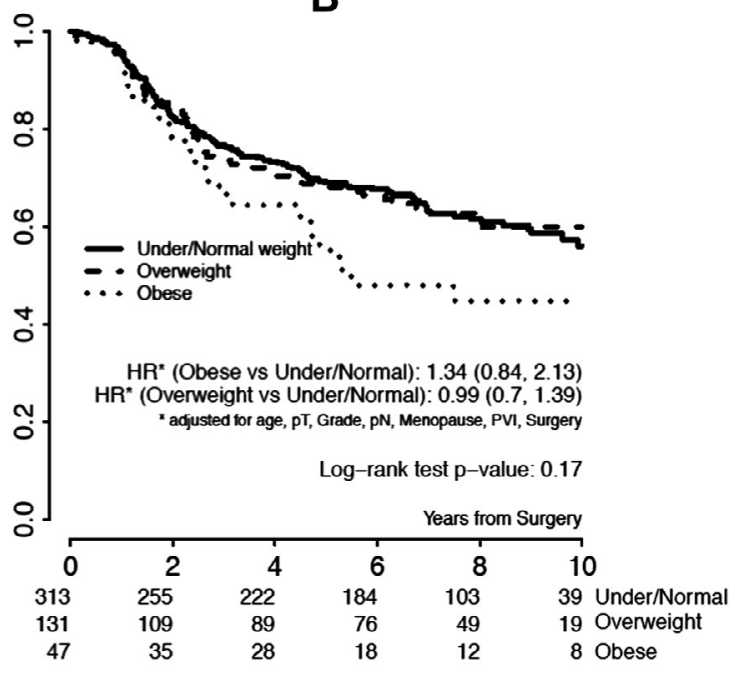

C

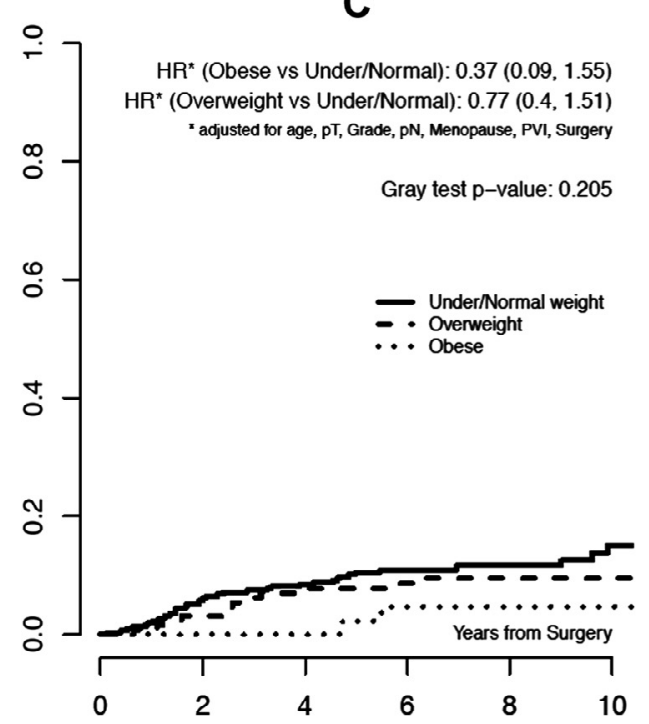

D

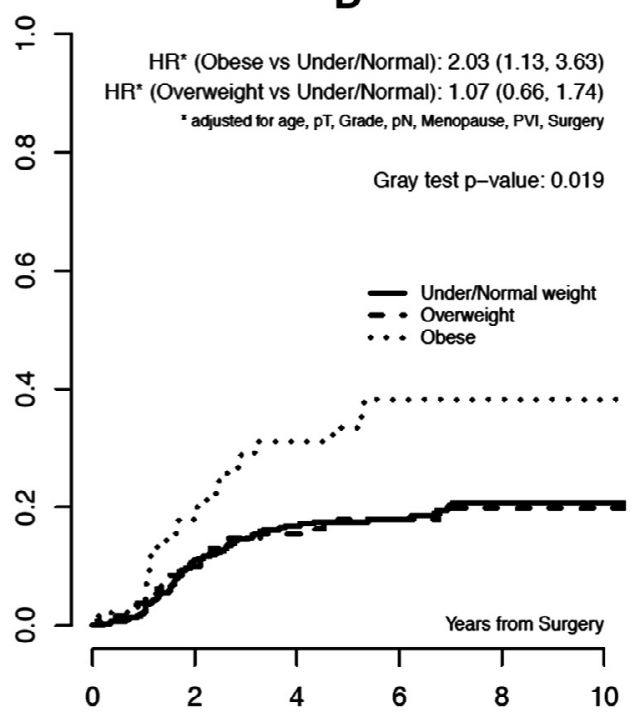

Fig. 2. Overall survival (panel A), disease-free survival (panel B), cumulative incidence of local and regional (LR) recurrence (panel C) and cumulative incidence of distant metastasis (DM) (Panel D), for the 491 patients with oestrogen receptor-negative (ER-)/HER2- breast cancer, by body mass index category. Univariate log-rank and Gray test $p$-values and hazard ratios (HRs) adjusted for age, pT, Grade, pN, Menopause, peritumoural vascular invasion (PVI), Surgery, are reported.

confounding due to temporal dis-homogeneity in treatment, as the introduction of Trastuzumab radically altered the natural history of this disease. Ongoing retrospective analyses within the Herceptin Adjuvant HERA and the North American Breast Cancer Group trials, for which this study may provide a historical comparison, will address the issue of whether BMI is a predictive factor for patients' response to adjuvant Trastuzumab therapy.

We used the standard WHO BMI categorisation and included our small number of underweight cases into the normal weight group. We stratified patients according to oestrogen receptor status, as this separates two clinically and biologically distinct groups of HER2+ patients. ${ }^{8,11}$
The main finding of our study is that, within HER2+ tumours, lack of oestrogen receptor expression separates patients in which obesity correlates with worse outcome from those in which it does not: only ER- obese patients had a significantly worse overall survival compared with underweight/normal or overweight patients (HR of 1.79). In the same group the HR for DFS was 1.34 but did not reach statistical significance. However, the number of distant metastases was more than double in obese patients (HR 2.03, $p$-value 0.019), whereas local recurrence showed a slightly lower, albeit not significant, incidence. This pattern is in agreement with previous data on a large unsorted population, ${ }^{3}$ and suggests that an apparently modest effect on combined outcome parameters (such as DFS) may be due to the contrasting 
Table 3

Multivariate analysis, by oestrogen receptor status.

\begin{tabular}{|c|c|c|c|c|c|c|c|c|c|}
\hline & & \multicolumn{2}{|l|}{ Overall survival $(\mathrm{OS})$} & \multicolumn{2}{|c|}{$\begin{array}{l}\text { Disease-free survival } \\
\text { (DFS) }\end{array}$} & \multicolumn{2}{|c|}{$\begin{array}{l}\text { Local and regional } \\
\text { (LR) }\end{array}$} & \multicolumn{2}{|c|}{ Distant metastasis $(\mathrm{DM})$} \\
\hline & & $\begin{array}{l}\text { Hazard ratio }(\mathrm{HR}) \\
(95 \% \text { confidence } \\
\text { interval }(\mathrm{CI}))\end{array}$ & $p$ & $\operatorname{HR}(95 \% \mathrm{CI})$ & $p$ & $\operatorname{HR}(95 \% \mathrm{CI})$ & $p$ & $\operatorname{HR}(95 \% \mathrm{CI})$ & $p$ \\
\hline \multicolumn{10}{|c|}{ Oestrogen receptor-positive (ER+) group } \\
\hline \multirow[t]{2}{*}{$\begin{array}{l}\text { Body mass } \\
\text { index } \\
\text { (BMI) }\end{array}$} & $\begin{array}{l}\text { Obese versus } \\
\text { under/normal } \\
\text { weight }\end{array}$ & $1.05(0.53 ; 2.09)$ & 0.91 & $0.75(0.43 ; 1.31)$ & 0.31 & $0.38(0.09 ; 1.57)$ & 0.18 & $0.81(0.36 ; 1.84)$ & 0.62 \\
\hline & $\begin{array}{l}\text { Overweight } \\
\text { versus under/ } \\
\text { normal weight }\end{array}$ & $0.77(0.46 ; 1.26)$ & 0.29 & $0.88(0.63 ; 1.23)$ & 0.45 & $0.82(0.43 ; 1.58)$ & 0.54 & $0.90(0.54 ; 1.50)$ & 0.68 \\
\hline $\begin{array}{l}\text { Menopausal } \\
\text { status }\end{array}$ & Pre versus post & $1.10(0.62 ; 1.95)$ & 0.76 & $0.99(0.67 ; 1.48)$ & 0.97 & $0.99(0.45 ; 2.16)$ & 0.97 & $0.89(0.50 ; 1.60)$ & 0.70 \\
\hline $\mathrm{pT}$ & $2 / 3 / 4$ versus 1 & $1.35(0.89 ; 2.06)$ & 0.16 & $1.31(0.99 ; 1.74)$ & 0.06 & $0.90(0.52 ; 1.54)$ & 0.69 & $1.61(1.04 ; 2.48)$ & 0.03 \\
\hline $\begin{array}{l}\text { Positive } \\
\text { lymph }\end{array}$ & $\begin{array}{l}1-3 \text { versus } \\
\text { none }\end{array}$ & $1.30(0.79 ; 2.13)$ & 0.30 & $0.96(0.69 ; 1.34)$ & 0.82 & $0.80(0.44 ; 1.46)$ & 0.47 & $1.31(0.78 ; 2.20)$ & 0.31 \\
\hline nodes (LN) & $4+$ versus none & $2.85(1.74 ; 4.68)$ & $<0.001$ & $2.10(1.50 ; 2.95)$ & $<0.001$ & $1.06(0.53 ; 2.13)$ & 0.86 & $3.37(2.01 ; 5.65)$ & $<0.001$ \\
\hline Grade & $1-2$ versus 3 & $0.58(0.38 ; 0.86)$ & 0.01 & $0.80(0.61 ; 1.05)$ & 0.10 & $0.69(0.42 ; 1.15)$ & 0.15 & $0.69(0.46 ; 1.04)$ & 0.08 \\
\hline $\begin{array}{l}\text { Peritumoural } \\
\text { vascular } \\
\text { invasion } \\
\text { (PVI) }\end{array}$ & $\begin{array}{l}\text { Present versus } \\
\text { absent }\end{array}$ & $1.20(0.78 ; 1.83)$ & 0.41 & $1.28(0.95 ; 1.71)$ & 0.10 & $1.6(0.94 ; 2.73)$ & 0.08 & $1.09(0.70 ; 1.69)$ & 0.71 \\
\hline Surgery & $\begin{array}{l}\text { Conservative } \\
\text { versus } \\
\text { mastectomy }\end{array}$ & $0.72(0.47 ; 1.09)$ & 0.12 & $0.84(0.63 ; 1.11)$ & 0.22 & $1.0(0.57 ; 1.74)$ & 0.99 & $0.66(0.43 ; 0.99)$ & 0.05 \\
\hline Age & $\begin{array}{l}+10 \text { years } \\
\text { increase }\end{array}$ & $1.32(1.03 ; 1.69)$ & 0.03 & $1.09(0.91 ; 1.29)$ & 0.36 & $1.0(0.71 ; 1.42)$ & 1.00 & $0.95(0.74 ; 1.23)$ & 0.72 \\
\hline \multicolumn{10}{|c|}{$E R$ negative (ER-) group } \\
\hline \multirow[t]{2}{*}{ BMI } & $\begin{array}{l}\text { Obese versus } \\
\text { under/normal } \\
\text { weight }\end{array}$ & $1.79(1.03 ; 3.10)$ & 0.04 & $1.34(0.84 ; 2.13)$ & 0.22 & $0.37(0.09 ; 1.55)$ & 0.17 & $2.03(1.13 ; 3.63)$ & 0.02 \\
\hline & $\begin{array}{l}\text { Overweight } \\
\text { versus under/ } \\
\text { normal weight }\end{array}$ & $1.16(0.75 ; 1.79)$ & 0.50 & $0.99(0.70 ; 1.39)$ & 0.94 & $0.77(0.40 ; 1.51)$ & 0.45 & $1.07(0.66 ; 1.74)$ & 0.78 \\
\hline $\begin{array}{l}\text { Menopausal } \\
\text { status }\end{array}$ & Pre versus post & $1.13(0.63 ; 2.05)$ & 0.68 & $1.00(0.63 ; 1.60)$ & 0.99 & $2.05(0.84 ; 5.02)$ & 0.12 & $0.74(0.39 ; 1.42)$ & 0.37 \\
\hline $\mathrm{pT}$ & $2 / 3 / 4$ versus 1 & $1.57(1.04 ; 2.36)$ & 0.03 & $1.53(1.11 ; 2.10)$ & 0.01 & $1.21(0.66 ; 2.23)$ & 0.54 & $1.62(1.04 ; 2.53)$ & 0.03 \\
\hline \multirow[t]{2}{*}{ Positive LN } & $\begin{array}{l}1-3 \text { versus } \\
\text { none }\end{array}$ & $1.73(1.02 ; 2.91)$ & 0.04 & $1.68(1.14 ; 2.48)$ & 0.01 & $1.07(0.50 ; 2.32)$ & 0.86 & $2.62(1.48 ; 4.64)$ & $<0.001$ \\
\hline & $4+$ versus none & $2.53(1.52 ; 4.21)$ & $<0.001$ & $2.75(1.86 ; 4.07)$ & $<0.0001$ & $2.26(1.09 ; 4.69)$ & 0.03 & $4.04(2.27 ; 7.20)$ & $<0.001$ \\
\hline Grade & $1-2$ versus 3 & $0.58(0.32 ; 1.04)$ & 0.07 & $0.91(0.63 ; 1.32)$ & 0.62 & $1.11(0.57 ; 2.16)$ & 0.77 & $0.64(0.36 ; 1.16)$ & 0.14 \\
\hline PVI & $\begin{array}{l}\text { Present versus } \\
\text { absent }\end{array}$ & $1.87(1.21 ; 2.88)$ & $<0.001$ & $1.22(0.87 ; 1.71)$ & 0.24 & $0.83(0.41 ; 1.67)$ & 0.60 & $1.52(0.96 ; 2.39)$ & 0.07 \\
\hline Surgery & $\begin{array}{l}\text { Conservative } \\
\text { versus } \\
\text { mastectomy }\end{array}$ & $1.11(0.75 ; 1.64)$ & 0.60 & $1.45(1.05 ; 1.98)$ & 0.02 & $2.26(1.15 ; 4.41)$ & 0.02 & $1.19(0.78 ; 1.82)$ & 0.41 \\
\hline Age & $\begin{array}{l}+10 \text { years } \\
\text { increase }\end{array}$ & $1.02(0.78 ; 1.32)$ & 0.91 & $0.92(0.75 ; 1.14)$ & 0.45 & $1.28(0.87 ; 1.90)$ & 0.21 & $0.72(0.53 ; 0.97)$ & 0.03 \\
\hline
\end{tabular}

association of obesity with local versus distant events. Treating BMI as a continuous variable showed a typical U-shaped correlation with distant metastases, consistent with what observed in previous BMI-cancer mortality studies. ${ }^{17}$ Thus, categorising patients according to the standard WHO classification, ${ }^{12}$ which is based on cutoff points arbitrarily derived from heterogeneous BMI association studies, may inaccurately reflect the continuous relationship between BMI and cancer outcome variables.
As a whole, outcome was not significantly different between BMI classes in HER2+ tumours, in agreement with the only other study, to date, that separately evaluated HER2+ tumours. ${ }^{18}$ No significant differences could be identified within the ER+/HER $2+$ group. This is consistent with recent data showing that adjuvant endocrine therapy is less effective in obese patients, but only when aromatase inhibitors are used, whereas minimal or no differences are noticed with Tamoxifen. ${ }^{19,20}$ Although we do not have detailed information on the 


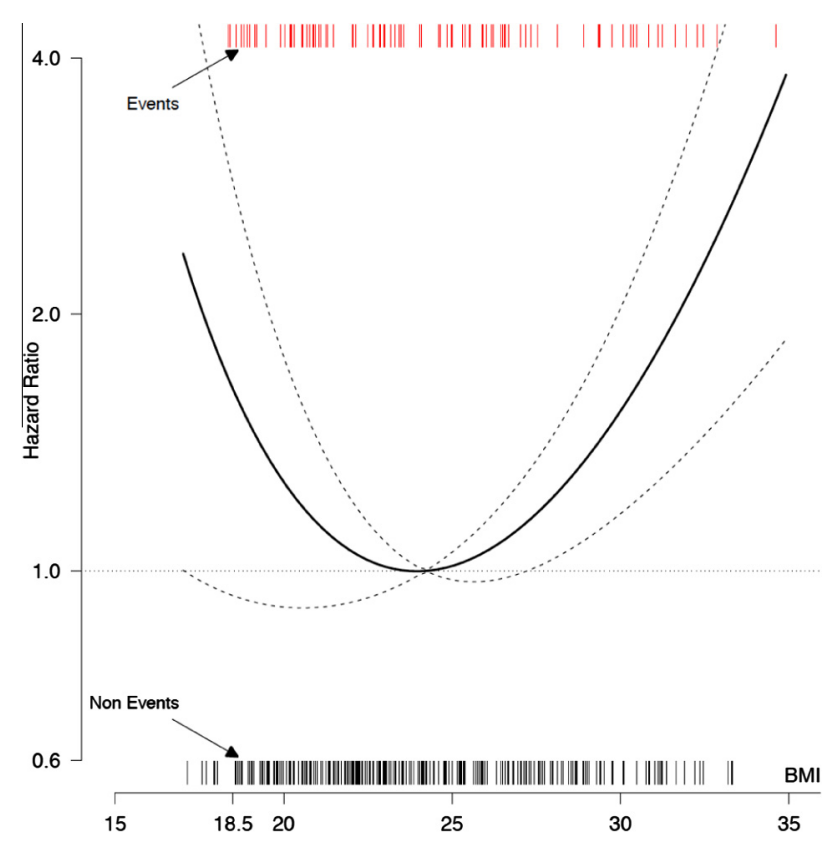

Fig. 3. Relationship between body mass index (BMI), on a continuous scale, and the hazard of distant metastases, in patients with HER2 positive and oestrogen receptor (ER)-negative breast cancer. The relationship is modelled by multivariable fractional polynomials (bold line). Model-based 95\% CIs are also reported (dashed lines). The median BMI value (24.2) was considered as the reference value in the estimation of the hazard ratio. Estimates were adjusted for age, pT, Grade, pN, Menopause, peritumoural vascular invasion (PVI), Surgery in a Cox proportional hazard model. The rug plots placed at the top and bottom of the graph show the BMI values in patients that relapsed (top) and in those who did not (bottom).

type of endocrine therapy in our population, given the time window of our analysis it is likely that the vast majority of our patients received Tamoxifen as adjuvant.

Our study has a number of strengths: long median follow-up (8.2 years); detailed treatment history; direct measurement of BMI variables; availability of patientlevel data, as opposed to study-level data, which reduces the risk of selection bias and provides results which are closer to everyday clinical practice. Weaknesses are the absence of information on treatment dosage, the retrospective nature of the analysis and the relatively small number of obese patients $(8.1 \%)$ in the cohort. Such small prevalence of obesity is in line with the general prevalence in Italy at the time, ${ }^{15}$ which has only marginally increased in the more recent years and it is significantly smaller than in other Western Countries. ${ }^{16}$

In theory, the poorer outcome of ER-/HER2+ obese patients can be explained by differences in treatment administration and/or biological susceptibility to obesity. Although we do not have information on systemic therapy dosing, treatment variables seem unlikely candidates as: (i) there was no significant difference in the percentage of patients receiving chemotherapy between BMI classes; (ii) the relatively higher frequency of conservative surgery in obese patients, which is the most evident treatment difference, should more probably affect local recurrence than distant metastases, and this is not the case in our study and (iii) there was no effect in ER+ tumours, which served as a control group in this respect.

We favour a model in which the biology of ER-/ HER2+ tumours makes them more prone to metastasisation in response to systemic metabolic alterations. Oestrogen, often invoked as the main mediator of obesityrelated progression in breast cancer, does not seem to play a role in this case. Instead, the pattern of relapse described here would suggest an interaction with pathways implicated in metastasis. On a speculative note, one likely candidate in this sense may be the Transforming Growth Factor beta (TGFb) pathway, as suggested by preclinical data showing that (i) increased TGFb levels favour metastases in a mouse model of ER -/HER2+ spontaneous tumourigenesis ${ }^{21}$ which responds to high fat $\operatorname{diet}^{22}$ and (ii) TGFb plays a crucial role in systemic metabolic control, indeed its circulating levels are dramatically increased in diet-induced or genetic models of obesity. ${ }^{23}$ Other mechanisms can also be implicated, such as angiogenesis ${ }^{21}$ and inflammatory cytokine imbalance, ${ }^{24}$ both of which are perturbed in obese organisms. ${ }^{25,26}$

Our results highlight the importance of the underlying tumour biology in evaluating BMI as a prognostic factor in breast cancer. This may have important consequences for the interpretation and design of dietary intervention trials. For instance, in the Women's Intervention Nutrition Study (WINS), the positive effects of dietary fat reduction on outcome were more evident in ER - tumours, ${ }^{4}$ in agreement with our hypothesis that lack of an oestrogen receptor identifies tumours inherently more susceptible to systemic metabolism. However, in the WINS, outcome differences did not reach statistical significance. Stratification for HER2 and ER status could help improve the identification of patients whose cancer prognosis can benefit from weight loss.

\section{Funding source and role of funding}

This work was supported by a grant from the Fondazione Umberto Veronesi to L.M. and funding from Boehringer Ingelheim Italia and the Italian Ministry of Health to P.G.P. We thank Paola Dalton for manuscript editing and language revision.

\section{Conflict of interest statement}

None declared.

\section{Appendix A. Supplementary data}

Supplementary data associated with this article can be found, in the online version, at http://dx.doi.org/ 10.1016/j.ejca.2013.07.016. 


\section{References}

1 Protani M, Coory M, Martin JH. Effect of obesity on survival of women with breast cancer: systematic review and meta-analysis. Breast Cancer Res Treat 2010;123(3):627-35.

2 Niraula S, Ocana A, Ennis M, Goodwin PJ. Body size and breast cancer prognosis in relation to hormone receptor and menopausal status: a meta-analysis. Breast Cancer Res Treat 2012;134(2): 769-81.

3 Ewertz M, Jensen M-B, Gunnarsdóttir KÁ, et al. Effect of obesity on prognosis after early-stage breast cancer. J Clin Oncol 2011; 29(1):25-31.

4 Chlebowski RT, Blackburn GL, Thomson CA, et al. Dietary fat reduction and breast cancer outcome: interim efficacy results from the Women's Intervention Nutrition Study. J Natl Cancer Inst 2006;98(24):1767-76.

5 Pierce JP, Caan BJ, Parker BA, et al. Influence of a diet very high in vegetables, fruit, and fiber and low in fat on prognosis. JAMA 2007;298(3):289-98.

6 Gonzalez-Angulo AM, Meric-Bernstam F. Metformin: a therapeutic opportunity in breast cancer. Clin Canc Res 2010;16(6): 1695-700.

7 Ligibel JA, Goodwin PJ. NEW and RENEW: building the case for weight loss in breast cancer. J Clin Oncol 2012;30(19):2294-6.

8 Goldhirsch A, Wood WC, Coates AS, Gelber RD, Thürlimann B, Senn H-J. Strategies for subtypes - dealing with the diversity of breast cancer: highlights of the St. Gallen International Expert Consensus on the Primary Therapy of Early Breast Cancer 2011. Ann Oncol 2011;22(8):1736-47.

9 Conroy SM, Maskarinec G, Wilkens LR, White KK, Henderson BE, Kolonel LN. Obesity and breast cancer survival in ethnically diverse postmenopausal women: the Multiethnic Cohort Study. Breast Cancer Res Treat 2011;129(2):565-74.

10 Berclaz G. Body mass index as a prognostic feature in operable breast cancer: the International Breast Cancer Study Group experience. Ann Oncol 2004;15(6):875-84.

11 Koboldt DC, Fulton RS, McLellan MD, et al. Comprehensive molecular portraits of human breast tumours. Nature 2012: $1-10$.

12 WHO. Physical status: the use and interpretation of anthropometry. Report of a WHO Expert Committee. Technical Report Series No. 854; 1995.
13 Kalbfleisch J, Prentice R. The statistical analysis of failure time data. Wiley and Sons Ltd; 1980.

14 Royston P, Ambler G, Sauerbrei W. The use of fractional polynomials to model continuous risk variables in epidemiology. Int J Epidemiol 1999;28(5):964-74.

15 Dal Maso L, Zucchetto A, Talamini R, et al. Effect of obesity and other lifestyle factors on mortality in women with breast cancer. Int J Cancer 2008;123(9):2188-94.

16 'Overweight and obesity - BMI statistics' Available from: http:// epp.eurostat.ec.europa.eu/statistics_explained/index.php/Overweight_and_obesity_BMI_statistics. [Retrieved on May 5th 2013].

17 Calle EE, Kaaks R. Overweight, obesity and cancer: epidemiological evidence and proposed mechanisms. Nat Rev Cancer 2004; 4(8):579-91.

18 Sparano JA, Wang M, Zhao F, et al. Obesity at diagnosis is associated with inferior outcomes in hormone receptor-positive operable breast cancer. Cancer 2012:1-10.

19 Pfeiler G, Königsberg R, Fesl C, et al. Impact of body mass index on the efficacy of endocrine therapy in premenopausal patients with breast cancer: an analysis of the prospective ABCSG-12 trial. J Clin Oncol 2011;29(19):2653-9.

20 Sestak I, Distler W, Forbes JF, Dowsett M, Howell A, Cuzick J. Effect of body mass index on recurrences in tamoxifen and anastrozole treated women: an exploratory analysis from the ATAC trial. J Clin Oncol 2010;28(21):3411-5.

21 Muraoka RS, Koh Y, Roebuck LR, et al. Increased malignancy of Neu-induced mammary tumors overexpressing active transforming growth factor $\beta 1$. Mol Cell Biol 2003;23(3):8691-703.

22 Chen C-T, Du Y, Yamaguchi $\mathrm{H}$, et al. Targeting the IKK $\beta /$ mTOR/VEGF signaling pathway as a potential therapeutic strategy for obesity-related breast cancer. Mol Cancer Ther 2012; 11(10):2212-21.

23 Yadav H, Quijano C, Kamaraju AK, et al. Protection from obesity and diabetes by blockade of TGF- $\beta /$ Smad 3 signaling. Cell Metab 2011;14(1):67-79.

24 Hartman ZC, Yang X-Y, Glass O, et al. HER2 overexpression elicits a proinflammatory IL-6 autocrine signaling loop that is critical for tumorigenesis. Cancer Res 2011;71(13):4380-91.

25 Christiaens V, Lijnen HR. Angiogenesis and development of adipose tissue. Mol Cell Endocrinol 2010;318(1-2):2-9.

26 Gregor MF, Hotamisligil GS. Inflammatory mechanisms in obesity. Ann Rev Immunol 2011;29(1):415-45. 